they also form the bulk of patients described in most follow-up studies quoted by Dr. Sim (e.g., Ekblad, Siegfried, etc.). Dr. Sim very surprisingly does not mention this group, unless they are included in his dismissal of socio-economic cases. They are of course not the same, and in Scandinavia, where socio-economic grounds are recognized by the law as indicators for termination, investigators like Ekblad, ${ }^{1}$ Höök, ${ }^{2}$ and others keep these groups strictly separate. Personality disorders or abnormal ingrained attitudes which make the patient vulnerable depend on their clinical course, and in the disability they cause to the patient, on all types of circumstances, and a continued pregnancy may well affect such a condition adversely. The continued pregnancy in such a case would not affect the patient in a physical sense, but would aggravate her condition as a psychological factor. This being so, termination of the pregnancy could well be indicated in such cases on psychiatric grounds within the meaning of the law.

If I may quote from Selma Siegfried's" summary of her investigation of 61 women: "Even with the most circumspect assessment of the indications for termination there will be individual cases in which the termination will have an unfavourable influence on the woman's inner development, and may perhaps do more harm than would have happened had the pregnancy been allowed to continue to term. The necessity of avoiding every kind of dogmatism in one's assessment of the indications for termination is again confirmed, and every case has to be studied individually; in doing so one must take into consideration not only the possible harm childbirth may cause but must equally take into account the possible harm that can come from hurting her maternal or her religious feelings or her general moral attitude towards termination."

If it is often pointed out that it is always very difficult to assess whether the continuation of a pregnancy is liable to adversely affect the mother suffering from a personality disorder or from an abnormal psychogenic development, to what degree and whether permanently or not, no one with any experience in the matter will doubt the truth of that. When it is further pointed out that there is very little evidence or exact knowledge on this problem, this has to be admitted. I do not want to appear ungrateful, but Dr. Sim's long-drawn-out and patient investigation certainly has not added to our knowledge on this difficult problem; in fact he seems to have either ignored or overlooked it entirely.-I am, etc.,

$$
\begin{aligned}
& \text { University of Manchester, } \\
& \text { Manchester } 13 . \\
& \text { REFERENCES }
\end{aligned}
$$

Ekblad, M.,

Höök, K., ibid., 1963, 39, Suppl. 168.

3 Stegfried, S., Schweiz. Arch. Neurol. Psychiat., 1951, 67, 365 .

** This correspondence is now closed.ED., B.M.J.

\section{Psychiatry and the Medical Curriculum}

SIR,--In view of your recent articles concerning the teaching of psychiatry to medical students, it may be of some in terest to have a brief review of the course as taught at the University of California in Los Angeles. I must point out that this is not necessarily typical of other universities in America.

During the four years of medical training, where preclinical and clinical years are not as sharply divided as in England, a total of 542 hours are spent in the study of psychiatry, with a further 150 hours elective teaching. In the first year the introductory course outlines the field of psychiatry, showing its relationships to the other branches of medicine, together with a description of personality development. It is intended to serve as a basis for the study of psychopathology and clinical work in later years. The work of the second year includes a detailed study of the classification of the mental disorders and their pathology. Instruction in psychiatric history-taking is also given.

One hundred and twenty hours are spent in the third year as an out-patient clinical clerk in which the principles of psychotherapy are studied as applied to general medical practice. A further 105 hours are spent in child psychiatry, integrated with the paediatric department. A similar period in the fourth year is spent as an in-patient clinical clerk, and there is a further short course on the psychiatric aspects of general clinical medicine During the 150 hours' elective study, the student can choose from the following courses: psychiatric emergency room work, social psychiatry, psychological development in early infancy, and psychosomatic medicine. All students take one of these. The 542 mandatory hours make up one-tenth of the total curriculum for the M.D. degree. This is considerably more than the comparable situation in England.

In light of Professor Denis Hill's (September 7. p. 581) proposed objectives, one sees here an important attempt not only to emphasize the role of psychiatric training for the student, but also to integrate it with the other branches of medicine.I am, etc.,

\section{Neuropsychiatric Institute \\ Los Angeles 24, Calif., U.S.A.}

SIR,-It is relatively easy to teach students those areas of psychiatry where a particular illness can be regarded as having symptoms, signs, and an appropriate physical treatment. The part of psychiatry which is difficult both to learn and to teach is what to do next with the neurotic patient after a sympathetic approach and a small dose of a tran- quillizer have failed to help. This is where the G.P. really needs to feel competent. It would seem that this field represents the most pressing central problem in the teaching of psychiatry. Professor D. Hill (September 7, p. 581) and Dr. J. Ellis (September 7, p. 585) both agree that psychology is essential in the preclinical curriculum and that its main field, as yet, of useful application is in the understanding of neurotic illness. The logical extension of this view is surely that clinical students must be taught how to make some sort of psychodynamic formulation to explain how a particular patient develops or maybe needs his symptoms. It also follows that it may be necessary to break away from the analogy with organic illness and disease labels and have the courage to teach students something of psychopathology. How else can they understand their own attitudes of hostility or dependency that Professor Hill mentions in his third objective? Ball and Wolff have shown ${ }^{1}$ that a substantial minority of students want to learn something of more formal psychotherapy and that they can be helped to do this.

Dr. Ellis feels that this deeper approach should be postponed until the intern year. It is, however, very difficult-especially in regional board hospitals - to imagine physicians postponing their rounds or surgeons arranging their lists so that the housemen can go off to discussions with the psychiatrist from the area mental hospital during one of his two busy weekly sessions.

The Sheffield type of interdepartmental teaching must come within the next few years in many spheres of medicine as well as in psychiatry. It may be that this represents the best available use of too few psychiatric teachers, but one wonders whether more should not be asked of their special departments. More use could be made of one-way screens and of taped interviews. Patients who take "overdoses" should be used for teaching and their troubles should be discussed in detail away from the bedside. Qualified psychiatric social workers and senior mental nurses might also share something of the teaching load. The University College Hospital type of teaching, in which students learn by doing and are supervised in groups, could be more widely adopted.

Finally, it is axiomatic that most students will not bother with any subject in which there is no examination requirement. At Oxford there is a viva in E.N.T., eyes, or anaesthetics, and the candidate does not know which subject he faces until two hours beforehand. It may be that something of the sort would represent an acceptable alternative to an extra paper or series of compulsory questions.-I am, etc.,

Liverpool.

M. J. TARSH.

\footnotetext{
1 Ball, D., and Wolf, H. H., Lancet, 1963, 1, 214.
} 